\title{
Bilateral monopolies and location choice
}

\author{
Kurt R. Brekke ${ }^{\mathrm{a}, *}$, Odd Rune Straume ${ }^{\mathrm{b}}$ \\ a Department of Economics, Programme for Health Economics in Bergen, University of Bergen, Fosswinckelsgate \\ 6, N-5007 Bergen, Norway \\ ${ }^{\mathrm{b}}$ Institute for Research in Economics and Business Administration (SNF) and Department of Economics, \\ University of Bergen, Bergen, Norway
}

Received 21 January 2002; accepted 1 April 2003

Available online 2 July 2003

\begin{abstract}
We analyse how equilibrium locations in location-price games à la Hotelling are affected when firms acquire inputs through bilateral monopoly relations with suppliers. Assuming a duopoly downstream market with input price bargaining, we find that the presence of input suppliers changes the locational incentives of downstream firms in several ways, compared with the case of exogenous production costs. Bargaining induces downstream firms to locate further apart, despite the fact that input prices increase with the distance between the firms. Furthermore, the downstream firm facing the stronger input supplier has a strategic advantage and locates closer to the market centre.

(C) 2003 Elsevier B.V. All rights reserved.
\end{abstract}

JEL classification: L13; J51; R30

Keywords: Spatial competition; Location choice; Bilateral monopolies; Endogenous production costs

\section{Introduction}

In most models of endogenous location, interpreted either in geographical space or product space, firms are assumed to base their choice of location on a trade-off between capturing a larger share of the market and avoiding more intense competition. The former consideration would induce firms to locate close to each other, whereas the latter would point in the direction of the opposite. In the present paper we analyse a situation in which locational choice also affects firms' production costs. We do so by modelling a duopoly in

\footnotetext{
* Corresponding author. Fax: +47-55-58-9210.

E-mail addresses: kurt.brekke@econ.uib.no (K.R. Brekke), odd.straume@econ.uib.no (O.R. Straume).
} 
which downstream firms acquire inputs through bilateral monopoly relations with upstream input suppliers. Input prices are determined in simultaneous bargaining between each firm and its input supplier.

The existence of bilateral monopolies can be explained by the notion of asset specificity, which potentially creates a 'lock-in' effect. ${ }^{1}$ Sunk investments which increase the value of trade between a buyer (downstream firm) and seller (upstream firm) also creates a switching cost, which decreases the value, in relative terms, of any outside option. ${ }^{2}$ A typical example of such investments is irreversible R\&D expenditures. Another, more specific, example could be sunk marketing expenditures which create bilateral monopoly relations between a producer of a final good (upstream firm) and a local distributor (downstream firm).

We believe that the most obvious, and perhaps most relevant, example of bilateral monopoly is that of a firm with a unionised labour force, where wages are determined in bargaining between the firm and its trade union. With this interpretation, our model corresponds to the case of decentralised, or firm-specific, wage bargaining. The present paper is thus linked to the relatively rich literature on unionised oligopoly. Contributions to this field which use the assumption of firm-specific wage bargaining include Horn and Wolinsky (1988), Davidson (1988), Dowrick (1989), Bughin (1999), Grandner (2001) and Lommerud et al. (2003). It is also important to note that a bargaining model of this kind is relevant, as Booth (1995) and others have argued, even if the labour force is not organised in formal unions. Investments in specific human capital ('asset specificity'), hiring and firing costs, search frictions and legal barriers are likely to give the work force of a particular firm some bargaining power even in the absence of unions.

Building on the classic work of Hotelling (1929), the 'standard' model of endogenous location is probably D'Aspremont et al. (1979). With uniformly distributed consumers and quadratic transportation costs they established the 'Principle of Maximum Differentiation': firms will choose to locate at the endpoints of the market. In subsequent years, various attempts to challenge this result have resulted in a sizeable body of theoretical work on this particular subject. The most common research strategy has been to introduce stronger centripetal forces in the model. A more concentrated consumer density, ${ }^{3}$ elastic demand ${ }^{4}$ or binding reservation prices ${ }^{5}$ are shown to yield more concentrated locations. By introducing R\&D externalities between the firms, Mai and Peng (1999) also get similar results. Economides (1986) demonstrates that the principle of maximum differentiation does not hold in general, but only for sufficiently convex transportation costs. Jehiel (1992) and Friedman and Thisse (1993) show that price collusion could lead to more concentrated locations as well. To our knowledge, though, no attempt has been made to analyse location choices with endogenous production costs. ${ }^{6}$

\footnotetext{
${ }^{1}$ See, e.g., Williamson (1983) and Riordan and Williamson (1985).

2 A number of empirical studies support the notion of asset specificity as explanation for vertical linkages of this kind. See Joskow (1991) for a survey.

3 See, e.g., Neven (1986), Tabuchi and Thisse (1995) and Anderson and Goeree (1997).

4 See, e.g., Böckem (1994) and Rath and Zhao (2001).

5 See, e.g., Wang and Yang (1999).

6 In a very different setting, with spatial price discrimination, Gupta et al. (1994) analyse a location game in which input prices are set by an upstream monopolist.
} 
Our purpose is not to challenge the Principle of Maximum Differentiation. Rather, we want to analyse how bilateral monopoly relations between upstream and downstream firms affect the incentives for relocation in the downstream market, compared with the case in which downstream firms buy their inputs from a competitive upstream market. The crucial aspect of the model is the endogenisation of production costs. Since different locations will yield different bargaining outcomes, the choice of location is not only governed by considerations for market shares and the degree of inter-firm competition. Firms must also take into account how their choice of location affects production costs. ${ }^{7}$

In order to perform this analysis, we choose to apply the standard assumptions of unit demand, uniformly distributed consumers and quadratic transportation costs. Like Lambertini (1994, 1997) and Tabuchi and Thisse (1995), and in contrast to D'Aspremont et al. (1979), we do not confine the firms to choose locations within the market space. This approach, which is sometimes referred to as the 'unconstrained Hotelling model', allows us to avoid corner solutions. It is also a way to portray, albeit in a rather crude way, a certain degree of consumer concentration in the market, which seems to be a reasonable assumption, whether location is measured in geographical space or product space.

A priori, it is not obvious whether the endogenisation of production costs turns out to be a centrifugal or centripetal force in the model. Since input prices are increasing in the distance between downstream firms in our model, one would perhaps think that the firms would locate closer in order to lower production costs through increased competition between the input suppliers. However, the model predicts the opposite result: input suppliers with positive bargaining power always cause the firms to locate further apart. This apparently counter-intuitive result is due to the fact that endogenisation of production costs changes the degree of intensity in price competition between downstream firms as a response to relocation. A relocation in the direction of the rival firm not only reduces the input price for the firm relocating, but also for the rival firm. This makes the centrifugal force of inter-firm competition even stronger than in the case of exogenous production costs. Furthermore, we find that bargaining with a strong upstream firm is a considerable strategic advantage for downstream firms in the location game. The firm with the stronger input supplier will always locate closer to the market centre than its competitor.

We also extend the basic model by analysing the case in which firms enter the market sequentially. Compared with the equivalent case of exogenous production costs, ${ }^{8}$ the presence of bilateral monopolies implies that the first-mover advantage is either reinforced or mitigated, depending on which firm has the strategic advantage of facing the stronger input supplier.

The rest of the paper is organised as follows: after presenting the basic model in Section 2 , the implications of endogenous production costs for the locational incentives of downstream firms are analysed in Section 3. In Section 4 we extend the model to consider the case of sequential location choice. In Section 5, some of the welfare implications of the model are considered, and, finally, some concluding remarks are offered in Section 6.

\footnotetext{
${ }^{7}$ Mayer (2000) also assumes that production costs vary across locations. However, with the assumptions of exogenous production costs and discriminatory pricing this paper is quite different from ours.

${ }^{8}$ With exogenous production costs, Tabuchi and Thisse (1995) find that the first entrant will locate at the market centre, revealing a strong first-mover advantage.
} 


\section{Model}

There are two firms selling products 1 and 2 at prices $p_{1}$ and $p_{2}$, respectively. The products differ with respect to a one-dimensional characteristic, measured by $x \in R$. Whereas $x$ in principle can take any real value, we assume that consumer preferences are characterised by a variable $z \in[0,1]$, implying that consumer $k$ has a 'most preferred product', given by $z^{k}$. For simplicity, we assume that $z$ is uniformly distributed on $[0,1]$, with unit mass.

Assuming unit demand, each consumer buys one unit of the good from either of the firms. If consumer $k$ buys the good from firm $i$, her utility is given by

$$
U_{i}^{k}=V-p_{i}-t\left(z^{k}-x_{i}\right)^{2}, \quad i=1,2 .
$$

The third term on the right hand side of (1) reflects the disutility associated with buying a product that differs from the consumer's most preferred product. This 'transportation cost' is assumed to be a quadratic function of distance. Consumers maximise utility by choosing to buy the good from the firm with the lower full price, i.e., mill price plus transportation cost. The reservation price $V$, assumed to be equal across consumers, is sufficiently high for the market always to be covered.

Firms produce the good using an input factor $l$ in a constant-returns-to-scale technology, in which one unit of $l$ produces one unit of output. This technology is assumed to be independent of firms' locations. ${ }^{9}$ Inputs are supplied to the downstream firms by independent input suppliers, with the input price $w_{i}$ being determined in bargaining between firm $i$ and its input supplier. The input suppliers' marginal costs of production are assumed to be equal, and are, without loss of generality, normalised to zero. Both upstream and downstream firms are assumed to be profit maximisers. If we interpret the upstream firms as trade unions, this would correspond to rent-maximising unions.

The profit function of firm $i$ is given by

$$
\pi_{i}=\left(p_{i}-w_{i}\right) Q_{i},
$$

where $Q_{i}$ is the aggregate demand for firm $i$ s product. We can derive the aggregate demand functions by using the following procedure: assume, without loss of generality, that $x_{1} \leq x_{2}$. When firms are located at $x_{1} \neq x_{2}$, let the location of the marginal consumer, who is indifferent between buying the good from either firm, be given by $\hat{z} \in(0,1)$. For this consumer the following equation must hold:

$$
p_{1}+t\left(\hat{z}-x_{1}\right)^{2}=p_{2}+t\left(x_{2}-\hat{z}\right)^{2} .
$$

Solving for $\hat{z}$, we find the marginal consumer to be located at

$$
\hat{z}=\frac{1}{2}\left(\frac{p_{2}-p_{1}}{t\left(x_{2}-x_{1}\right)}+x_{1}+x_{2}\right) \text {. }
$$

${ }^{9}$ Note that this is also an implicit assumption in standard models of location with exogenous and constant marginal costs. 
By the assumptions on the distribution of $z$, aggregate demand for firms 1 and 2, respectively, are given by

$$
\begin{aligned}
& Q_{1}=\int_{0}^{\hat{z}} f(z) \mathrm{d} z=\hat{z}, \\
& Q_{2}=\int_{\hat{z}}^{1} f(z) \mathrm{d} z=1-\hat{z},
\end{aligned}
$$

where $f(z)$ is the density function. Obviously, with uniform distribution on $[0,1]$ and unit mass, $f(z)=1$.

Reasonably claiming location choice to be the long-term decision of the players, we propose the following sequence of moves in the game:

Stage 1: firms simultaneously choose their locations, $x_{1}$ and $x_{2}$.

Stage 2: input prices $w_{1}$ and $w_{2}$ are determined in simultaneous and independent bargaining.

Stage 3: output prices $p_{1}$ and $p_{2}$ are simultaneously set by the downstream firms.

As usual, the model is solved by backwards induction.

\subsection{Stage 3: price competition}

Given the locations of the firms, $x_{1}$ and $x_{2}$, and the input prices, $w_{1}$ and $w_{2}$, the firms simultaneously set prices to maximise profits. The first-order condition for firm $i$ is given by

$$
Q_{i}+\left(p_{i}-w_{i}\right) \frac{\partial Q_{i}}{\partial \hat{z}} \frac{\partial \hat{z}}{\partial p_{i}}=0, \quad i=1,2
$$

Substituting (3) and (4)-(5) into (6) and solving yields

$$
\begin{aligned}
& p_{1}=\frac{t}{3}\left(2+x_{1}+x_{2}\right)\left(x_{2}-x_{1}\right)+\frac{1}{3}\left(2 w_{1}+w_{2}\right) \\
& p_{2}=\frac{t}{3}\left(4-x_{1}-x_{2}\right)\left(x_{2}-x_{1}\right)+\frac{1}{3}\left(2 w_{2}+w_{1}\right) .
\end{aligned}
$$

\subsection{Stage 2: bargaining}

We adopt the Nash bargaining model in a simultaneous bargaining setting, where the players in each bargaining unit negotiate over the input price assuming that an agreement will be reached within the other bargaining unit. For simplicity, the threat points of the 
bargaining parties are set equal to zero. The solution to the bargaining between firm $i$ and its input supplier is thus given by

$$
w_{i}=\arg \max \left(w_{i} l_{i}\right)^{\alpha_{i}} \pi_{i}^{1-\alpha_{i}}, \quad i=1,2,
$$

where $\alpha_{i} \in[0,1]$ is a measure of the relative bargaining strength of the input supplier of firm $i$.

Using the anticipated equilibrium prices in the subsequent subgame, (7)-(8), and imposing the technology $l_{i}=Q_{i}$, we can solve (9) to find the equilibrium input prices:

$$
\begin{aligned}
& w_{1}=\alpha_{1} t\left(x_{2}-x_{1}\right)\left[\frac{2\left(2+x_{1}+x_{2}\right)+\alpha_{2}\left(4-x_{1}-x_{2}\right)}{4-\alpha_{1} \alpha_{2}}\right] \\
& w_{2}=\alpha_{2} t\left(x_{2}-x_{1}\right)\left[\frac{2\left(4-x_{1}-x_{2}\right)+\alpha_{1}\left(2+x_{1}+x_{2}\right)}{4-\alpha_{1} \alpha_{2}}\right] .
\end{aligned}
$$

\subsection{Stage 1: location choice}

At the first stage of the game, the downstream firms simultaneously choose where to locate, each firm taking into account how its location affects input and output prices of both firms in subsequent stages of the game. Inserting (10)-(11) into (7)-(8), and thus eliminating input prices from the functional expressions of $p_{i}$, the first-order condition for firm $i$ 's optimal choice of location, derived from (2), can be expressed as:

$$
\left(\frac{\partial p_{i}}{\partial x_{i}}-\frac{\partial w_{i}}{\partial x_{i}}\right) Q_{i}+\left(p_{i}-w_{i}\right) \frac{\partial Q_{i}}{\partial \hat{z}}\left(\frac{\partial \hat{z}}{\partial x_{i}}+\frac{\partial \hat{z}}{\partial p_{i}} \frac{\partial p_{i}}{\partial x_{i}}+\frac{\partial \hat{z}}{\partial p_{j}} \frac{\partial p_{j}}{\partial x_{i}}\right)=0
$$

where $i, j=1,2$ and $i \neq j$. Substituting from (3), (4)-(5), (7)-(8) and (10)-(11) into (12), equilibrium locations are given by ${ }^{10}$

$$
\begin{aligned}
& x_{1}^{*}=\frac{-4+8 \alpha_{1}-16 \alpha_{2}+5 \alpha_{1} \alpha_{2}}{4\left(2-\alpha_{2}\right)\left(2-\alpha_{1}\right)} \\
& x_{2}^{*}=\frac{20+8 \alpha_{1}-16 \alpha_{2}-\alpha_{1} \alpha_{2}}{4\left(2-\alpha_{1}\right)\left(2-\alpha_{2}\right)} .
\end{aligned}
$$

\footnotetext{
10 The second-order conditions are satisfied, since $v \partial^{2} \pi_{i}\left(x_{1}^{*}, x_{2}^{*}\right) / \partial x_{i}^{2}=-v\left(2-\alpha_{1}\right)\left(2-\alpha_{2}\right) t / 2\left(4-\alpha_{1} \alpha_{2}\right)<0$.
} 
If input prices are exogenous, we know from Lambertini $(1994,1997)$ and Tabuchi and Thisse (1995) that equilibrium locations are given by $\left(x_{1}, x_{2}\right)=\left(-\frac{1}{4}, \frac{5}{4}\right) \cdot{ }^{11}$ In the context of our model, exogenous input prices would correspond to the case in which the downstream firms have all the bargaining strength, and could be interpreted as the firms buying inputs from a competitive upstream market, or being vertically integrated with their respective input suppliers. In this case there are two opposing forces governing the choice of location. From the viewpoint of firm $i$, by moving closer to its competitor the marginal consumer is, ceteris paribus, pushed in the same direction, implying that the firm will gain a larger share of the market. This is the market share effect, which is a centripetal force in the model. The downside of moving closer to its competitor, though, is that price competition between the firms becomes more intense. Consequently, the competition effect is a centrifugal force in the model.

\section{Location choice with input price bargaining}

When input prices are endogenous, the downstream firms must take into account how the outcome of input price bargaining is affected by the firms' locations. In order to analyse how this, in turn, affects the downstream firms' location choices, it is instructive first to consider how changes in the relative bargaining strengths of the players provide incentives for relocation. From (13) and (14) we can state the following comparative statics result:

Lemma 1. An increase in the relative bargaining strength of input supplier $i$ (input supplier $j$ ) will give firm $i$ an incentive to relocate towards (away from) firm $j$.

Proof. Taking partial derivatives in (13)-(14), we find that $\partial x_{1}^{*} \partial \alpha_{1}=$ $3 / 2\left(2-\alpha_{1}\right)^{2}>0, \partial x_{1}^{*} / \partial \alpha_{2}=-9 / 2\left(2-\alpha_{1}\right)^{2}<0, \partial x_{2}^{*} / \partial \alpha_{2}=-3 / 2\left(2-\alpha_{2}\right)^{2}<0$, $\partial x_{2}^{*} / \partial \alpha_{1}=9 / 2\left(2-\alpha_{2}\right)^{2}>0$.

If firm $i$ relocates towards its rival firm, the general effect is a reduction of equilibrium input prices. Closer location implies a more fierce competition on output prices between the downstream firms, and there are thus less profits for the input suppliers to extract through bargaining. In addition, tougher competition between the downstream firms implies that input suppliers also compete more fiercely, which means that the upstream firms will be more reluctant to push for high input prices, since total sales are more responsive to input price differentials when price competition between downstream firms is strong.

From the viewpoint of either firm, though, unilateral relocation has two opposing effects. Relocation by firm $i$ in the direction of firm $j$ leads to a reduction in production costs for firm $i$, which implies both a direct cost saving and, ceteris paribus, an improved competitive position towards firm $j$. However, such a relocation also leads to reduced production costs for firm $j$, which results in a more fierce price competition.

11 If the firms' location choices are restricted to the interval $[0,1]$ we would have equilibrium locations at the endpoints, as first shown by D'Aspremont et al. (1979). 
The relative strength of the two effects is determined by input price responses to relocation, which in turn is determined by the relative bargaining strength of the input suppliers. Input suppliers would optimally want to respond to relocations by adjusting their prices to maximise profits at all times. The extent to which they are able to do so is determined by their relative bargaining strengths. It is thus clear that input price responses to relocations are increasing with the relative bargaining strengths of upstream firms. From the viewpoint of firm $i$, a strong response by its own input supplier and a weak response by the input supplier of firm $j$ means that firm $i$ can improve its competitive position by relocating in the direction of its rival firm. For firm $j$, the incentives are opposite.

The important implication of the incentive mechanisms stated in Lemma 1 is that bargaining with a strong input supplier is a strategic advantage for downstream firms in the location game. To make this point more clear, consider the limit case in which only one of the downstream firms, say firm 1, has to enter into bargain with an upstream firm. This would correspond to the case of $\alpha_{2}=0 .{ }^{12}$ Now consider the relocation incentives of firm 1. By moving closer to firm 2 it can reduce its production costs without reducing the production costs of firm 2 , thus unambiguously improving its competitive position relative to its competitor. Firm 2, on the other hand, has exact opposite incentives.

The properties of the Nash equilibrium in locations when downstream firms are locked into bilateral monopolies with input suppliers are stated in the following Proposition:

Proposition 1.(i) Firm $i$ will locate closer to (further away from) the market centre than firm $j$ if $\alpha_{i}>(<) \alpha_{j}$.

(ii) The distance between the firms is increasing in $\alpha_{i}$ and $\alpha_{j}$.

(iii) Equilibrium profits are equal for both firms, and increasing in $\alpha_{i}$ and $\alpha_{j}$.

Proof. (i) Let $A \equiv \frac{1}{2}-x_{1}^{*}$ and $B \equiv x_{2}^{*}-\frac{1}{2}$ be measures of the distance from the market centre in equilibrium for firms 1 and 2, respectively. Without loss of generality, assume that $\alpha_{1}>\alpha_{2}$. From (13) and (14) we find that $A-B=v 6\left(\alpha_{2}-\alpha_{1}\right) /\left(2-\alpha_{1}\right)\left(2-\alpha_{2}\right)<0$.

(ii) Since $x_{1} \leq x_{2}$, it is sufficient to compare the partial derivatives; $\partial x_{2}^{*} / \partial \alpha_{1}-$ $\partial x_{1}^{*} / \partial \alpha_{1}=3 /\left(2-\alpha_{1}\right)^{2}>0$ and $\partial x_{2}^{*} / \partial \alpha_{2}-\partial x_{1}^{*} / \partial \alpha_{2}=3 /\left(2-\alpha_{2}\right)^{2}>0$.

(iii) Equilibrium profits are easily calculated to be

$$
\pi_{1}=\pi_{2}=\frac{3}{4} \frac{v\left(4-\alpha_{1} \alpha_{2}\right) t}{\left(2-\alpha_{1}\right)\left(2-\alpha_{2}\right)},
$$

which yields $\partial \pi_{i} / \partial \alpha_{j}=3 t / 2\left(2-\alpha_{j}\right)^{2}>0, i, j=1,2$.

The first part of the Proposition, which follows naturally from Lemma 1, demonstrates the strategic advantage of meeting a strong upstream firm in bargaining. Although the firm facing the stronger input supplier will have higher production costs, the locational incentives are such that this firm will locate closer to the market than its competitor, allowing the firm to charge a higher price for its final product.

12 Alternatively, this situation could be interpreted as firm 2 being vertically integrated with its input supplier, implying an input price equal to marginal production costs, i.e., $w_{2}=0$. It can easily be verified that this would yield the same result. 
Part (ii) of the Proposition implies that the presence of input price bargaining leads the downstream firms to locate further apart, compared with the case of exogenous production costs. The intuition behind this, perhaps somewhat surprising, result is strongly linked to the discussion of Lemma 1. We know from Lemma 1 that an increase in the relative bargaining power of one of the input suppliers provides the corresponding downstream firm with an incentive to relocate towards its rival. Ceteris paribus, this leads to a smaller distance between the firms. However, it also follows from Lemma 1 that the optimal response of the rival firm is to relocate further away, in order credibly to soften price competition through higher input prices. From the second part of Proposition 1 it is apparent that this second effect always dominates, implying that the distance between the firms is increasing in the relative bargaining strength of either input supplier.

Another interpretation of this result is that the competition effect from closer location is stronger when input prices are endogenous, due to strategic complementarity of output prices, and this more than offsets the gain from lower production costs. Compared with the case of exogenous production costs, the presence of input price bargaining provides downstream firms with incentives for raising rival's costs by locating further away.

Furthermore, this means that, by relocating in opposite directions, the increase in output prices, due to relaxed competition between the downstream firms, is larger than the increase in input prices. Consequently, profits in the downstream market are higher when the firms are faced with bargaining over input prices. An interesting implication is that downstream firms would actually prefer having bilateral monopoly relations with input suppliers, rather than facing a competitive upstream market, or being vertically integrated with their respective input suppliers. The reason is that the bargaining process serves as a credible device for softening price competition in the downstream market, yielding a higher total profit in the market. From (15) we see that equilibrium profits are always the same for both firms, implying that the strategic advantage of bargaining with the stronger input supplier always exactly offsets the cost disadvantage.

Comparing with equilibrium locations for the case of exogenous production costs, it can also be shown that firm $i$ will locate closer to the market centre if $\alpha_{i}>0$ and $\alpha_{j}=0$, or if the difference between $\alpha_{i}$ and $\alpha_{j}$ is sufficiently large. In the extreme case of $\alpha_{1}=1$ and $\alpha_{2}=0,{ }^{13}$ it follows from (13)-(14) that equilibrium locations are given by $\left(x_{1}=\frac{v 1}{2}, x_{2}=\frac{v 7}{2}\right)$. This resembles the outcome of sequential location in Tabuchi and Thisse (1995), where the first-mover locates at the market centre and the follower locates outside the market. In the subsequent section we will reconsider the case of sequential location in the light of the present model.

\section{Sequential location}

In some markets it may be more realistic to assume that firms enter the market sequentially, whereas bargaining and price competition remain simultaneous. In this

${ }^{13}$ In the context of labour input, this would correspond to a situation in which firm 1 is unionised (with a monopoly union), whereas firm 2 is non-unionised. 
particular extension of the model the game is now played in four stages. Firm 1 enters the market first, followed by the locational choice of firm 2 in the second stage of the game. In the third stage input prices are simultaneous determined through bargaining, whereas output prices are set in the final stage of the game.

As before, the natural benchmark for comparison is the case of exogenous input prices. From Tabuchi and Thisse (1995) we know that in this case there is a strong first-mover advantage, yielding $\left(x_{1}=\frac{v 1}{2}, x_{2}=\frac{v 3}{2}\right)$ as the equilibrium outcome.

Equilibrium locations when firms enter sequentially are derived by backwards induction, starting at stage 2 of the game. The first-order condition for firm 2's locational choice yields a best-reply function

$$
x_{2}=R\left(x_{1}\right)
$$

At the first stage of the game firm 1 enters the market, anticipating the response of the follower. Thus, the first-order condition for the optimal location of firm 1 is given by

$$
\frac{\partial \pi_{1}\left(x_{1}, R\left(x_{1}\right)\right)}{\partial x_{1}}+\frac{\partial \pi_{1}\left(x_{1}, R\left(x_{1}\right)\right)}{\partial x_{2}} \frac{\mathrm{d} R}{\mathrm{~d} x_{1}}=0
$$

Using the profit functions and the equilibrium expressions for input and output prices derived in the previous section, the solution to the sequential game enables the following statement:

Proposition 2. When firms enter the market sequentially, with firm 1 being the first entrant, then

(i) firm 1 locates at the market centre if $\alpha_{1} \geq \alpha_{2}$,

(ii) firm 1 locates away from the market centre if $\alpha_{1}<\alpha_{2}$,

(iii) the firms always locate further apart than if production costs are exogenous.

A proof is provided in Appendix A.

Proposition 2 illustrates that the outcome of the sequential game is potentially very different from the case of exogenous production costs considered by Tabuchi and Thisse (1995). If $\alpha_{1}<\alpha_{2}$, the first-mover advantage is mitigated by the strategic disadvantage of bargaining with a weak input supplier, causing the first entrant to locate away from the market centre, with the follower locating closer to the market, making equilibrium locations more symmetric around the market centre. In the extreme case of $\alpha_{1}=0$ and $\alpha_{2}=1$, the follower will actually locate closer to the market centre than the first entrant, with equilibrium locations given by $\left(x_{1}^{F}=-1, x_{2}^{F}=1\right)$.

In the opposite case, in which the first-mover also has the strategic advantage of bargaining with the stronger input supplier, the first entrant clearly can do no better than locating at the market centre, but the first-mover advantage is now reinforced in the sense that the follower will locate even further away from the market, compared with the case of exogenous production costs. The intuition follows straightforwardly from the analysis of the previous section. 


\section{Welfare implications}

With the assumptions of our model, an increase in input prices is a one-to-one monetary transfer from downstream to upstream firms, and with unit demand and a non-binding reservation price, an increase in output prices is similarly just a monetary transfer from consumers to downstream firms. This implies that welfare, measured as an unweighted sum of producers' and consumers' surplus, is only determined by total outlays on transportation costs. More precisely, maximising social welfare is equivalent to minimising consumers' transportation costs. ${ }^{14}$ In this case we know, as demonstrated by Hotelling (1929), that socially desirable locations require both firms to occupy symmetrical positions at the quartiles of the market, i.e., $x_{1}=\frac{1}{4}$ and $x_{2}=\frac{3}{4}$.

Compared with exogenous production costs, it can easily be shown that the presence of bilateral monopoly relations between input suppliers and downstream firms is always detrimental to social welfare. This follows from Proposition 1, which shows that input price bargaining induces the firms to locate further apart than in the case of exogenous production costs, leading to higher transportation costs for the consumers. This is not an immediately obvious result, though, since the more centrally located firm could potentially be serving the majority of consumers. However, inserting equilibrium locations and prices into (3), it is easily confirmed that the marginal consumer is always located at the market centre. Thus, the downstream firm facing the stronger input supplier exploits this strategic advantage by charging a relatively high price for the final product, always forcing half of the consumer mass to 'travel' to the more distantly located firm, which charges a lower price.

Considering the case of sequential entry to the market, input price bargaining could result in a smaller total outlay on transportation costs, compared with the case of exogenous production costs. If firm 1 is the first entrant, it is possible to show that the existence of bilateral monopolies increases social welfare if both $\alpha_{1}$ and $\alpha_{2}$ are small, and asymmetric in favour of $\alpha_{2}$. This is quite intuitive. When both input suppliers are weak, the centrifugal effect of input price bargaining, which is detrimental to social welfare, is quite small. If additionally the follower has the strategic advantage of bargaining with the stronger input supplier, the first-mover advantage is partly mitigated, yielding more symmetric equilibrium locations. When the distance between the firms is not too large, this second effect will dominate, causing social welfare to increase.

\section{Concluding remarks}

In industries which are characterised by upstream market power, downstream firms have potential incentives to act strategically in order to affect input prices, and thus

\footnotetext{
${ }^{14}$ Clearly, the assumption of unit demand has some rather strong implications for the analysis of social welfare, making total transportation costs the only relevant variable. It should be said that although this assumption may be a useful approximation for some markets, we would normally expect the 'standard' efficiency loss from pricing above marginal costs to prevail. In this sense, the present welfare analysis is somewhat 'partial', and consequently the results should be interpreted with the necessary degree of care.
} 
production costs. In the present paper we have analysed how bilateral monopoly relations between upstream and downstream firms affect the choice of location (or product differentiation) in the downstream market. Applying an 'unconstrained' Hotelling model we have shown that the presence of input price bargaining induces the downstream firms to locate further apart compared with the case of exogenous production costs. This means that the downstream firms have incentives to act strategically not to reduce own production costs, but rather to raise rival's costs. We have also identified a strategic advantage associated with facing a relatively strong upstream firm in bargaining, implying that the firm facing the stronger input supplier has an incentive to relocate towards its rival, while the rival has the opposite incentive.

Although one should be careful about putting too much emphasis on the welfare implications of spatial competition models with unit demand, we are nevertheless able to identify an additional, and hitherto unnoticed, inefficiency caused by upstream market power. In addition to the familiar inefficiency caused by 'double marginalisation', we show that the existence of bilateral monopolies also creates incentives for downstream firms to relocate further away from the market centre, reinforcing the reduction-ofcompetition effect that causes too much differentiation in the first place.

Finally, it should be noted that in order to facilitate analytical tractability when extending the Hotelling model to incorporate bargaining on input prices, assumptions regarding demand for the final product have been made as simple as possible, with uniform distribution of consumers, unit demand and non-binding reservation prices. With only two downstream firms this implies that the centrifugal forces in the model are very strong, perhaps unrealistically strong. As mentioned in the Introduction, there are several ways to incorporate stronger centripetal forces in the model. For instance, by making demand more elastic one would get locations closer to the market centre. However, our purpose has been to illustrate how the presence of input suppliers affects downstream firms' incentives to relocate, compared with the case of exogenous input prices, and these (partial) effects should be robust to a number of modifications to the original model.

\section{Acknowledgements}

We are indebted to Gianni De Fraja, Kjell Erik Lommerud, Lars Sørgard, Steinar Vagstad and two anonymous referees for valuable comments. This paper was partly written while Brekke was visiting the Centre for Health Economics at the University of York, and Straume was visiting the Department of Economics at the University of Warwick. The hospitalities of the respective institutions are gratefully acknowledged.

\section{Appendix A. Proof of Proposition 2}

(i)-(ii) Observe first that both firms occupying positions at the same side of the market centre cannot be an equilibrium in the location game when consumers are symmetrically distributed. If $x_{2}^{*}$ is the best response to $x_{1}=\frac{1}{2}-\Delta$, then, due to symmetry, $1-x_{2} *$ must be the best response to $x_{1}=\frac{1}{2}+\Delta$. It follows that $\pi_{i}\left(\frac{1}{2}-\Delta, x_{2} *\right)=\pi_{i}\left(\frac{1}{2}+\Delta, 1-x_{2} *\right)$ for 
$i=1,2$. Thus, it suffices to consider locations where $x_{1} \leq \frac{1}{2} \leq x_{2}$. Solving the first-order condition for firm 2, we find this firm's best response function to be given by

$$
R\left(x_{1}\right)=\frac{1}{3} \frac{\left(8+x_{1}\left(2-\alpha_{1}\right)+2 \alpha_{1}\right)}{2-\alpha_{1}} .
$$

Inserting (A.1) into the profit function of firm 1 and taking the partial derivative with respect to $x_{1}$, we derive

$$
\frac{\partial \pi_{1}\left(x_{1}, R\left(x_{1}\right)\right)}{\partial x_{1}}=\Psi \frac{4+4 \alpha_{1}+\alpha_{2} \alpha_{1}-8 \alpha_{2}-2 x_{1}\left(2-\alpha_{2}\right)\left(2-\alpha_{1}\right)}{\left(4-\alpha_{1} \alpha_{2}\right)^{2}},
$$

where

$$
\Psi=\frac{4}{81} t\left(20+2 x_{1}\left(2-\alpha_{2}\right)\left(2-\alpha_{1}\right)+8 \alpha_{2}-4 \alpha_{1}-7 \alpha_{2} \alpha_{1}\right) .
$$

Evaluating for $x_{1} \leq \frac{v 1}{2} \leq R\left(x_{1}\right)$, a closer inspection of (A.2) reveals that $\partial \pi_{1} / \partial x_{1}>0$ if $\alpha_{1}>\alpha_{2}$. If $\alpha_{1} \leq \alpha_{2}$, then $\partial \pi_{1} / \partial x_{1}=0$ for $x_{1} \leq \frac{v 1}{2}$ (with $\partial \pi_{1} / \partial x_{1}=0$ for $x_{1}=\frac{v 1}{2}$ if $\alpha_{1}=\alpha_{2}$ ).

(iii) From (A.1) and (A.2), equilibrium locations are given by

$$
\begin{aligned}
& x_{1}^{F}= \begin{cases}\frac{4+4 \alpha_{1}+\alpha_{2} \alpha_{1}-8 \alpha_{2}}{2\left(2-\alpha_{1}\right)\left(2-\alpha_{2}\right)} & \text { if } \alpha_{1}<\alpha_{2} \\
\frac{1}{2} & \text { if } \alpha_{1} \geq \alpha_{2}\end{cases} \\
& x_{2}^{F}= \begin{cases}\frac{12+4 \alpha_{1}-8 \alpha_{2}-\alpha_{2} \alpha_{1}}{2\left(2-\alpha_{2}\right)\left(2-\alpha_{1}\right)} & \text { if } \alpha_{1}<\alpha_{2} \\
\frac{6+\alpha_{1}}{2\left(2-\alpha_{1}\right)} & \text { if } \alpha_{1} \geq \alpha_{2}\end{cases}
\end{aligned}
$$

Now define $D \equiv x_{2}^{F}-x_{1}^{F}$ as the distance between the firms at equilibrium locations. From (A.3) and (A.4) we find that $D=4-\alpha_{1} \alpha_{2} /\left(2-\alpha_{2}\right)\left(2-\alpha_{1}\right)$ if $\alpha_{1}<\alpha_{2}$ and $D=$ $v 2+\alpha_{1} / 2-\alpha_{1}$ if $\alpha_{1} \geq \alpha_{2}$. Clearly, $D\left(\alpha_{1}, \alpha_{2}\right)>D(0,0)$.

\section{References}

Anderson, S.P., Goeree, J.K., 1997. Location, location, location. Journal of Economic Theory 77, 102-127.

D’Aspremont, C., Gabszewicz, J.J., Thisse, J.F., 1979. On Hotelling's 'Stability in competition'. Econometrica $47,1145-1150$. 
Booth, A., 1995. The Economics of the Trade Union. Cambridge University Press, Cambridge.

Bughin, J., 1999. The strategic choice of union-oligopoly bargaining agenda. International Journal of Industrial Organization 17, 1029-1040.

Böckem, S., 1994. A generalized model of horizontal product differentiation. Journal of Industrial Economics 42, 287-298.

Davidson, C., 1988. Multiunit bargaining in oligopolistic industries. Journal of Labor Economics 6, 397-422.

Dowrick, S., 1989. Union-oligopoly bargaining. Economic Journal 99, 1123-1142.

Economides, N., 1986. Product differentiation in Hotelling's duopoly. Economic Letters 21, 67-71.

Friedman, J.W., Thisse, J.-F., 1993. Partial collusion fosters minimum product differentiation. Rand Journal of Economics 24, 631-645.

Grandner, T., 2001. Unions in oligopolistic, vertically connected industries. European Economic Review 45, $1723-1740$.

Gupta, B., Kats, A., Pal, D., 1994. Upstream monopoly, downstream competition and spatial price discrimination. Regional Science and Urban Economics 24, 529-542.

Horn, H., Wolinsky, A., 1988. Bilateral monopolies and incentives for merger. Rand Journal of Economics 19, $408-419$.

Hotelling, H., 1929. Stability in competition. Economic Journal 39, 41-57.

Jehiel, P., 1992. Product differentiation and price collusion. International Journal of Industrial Organization 10, $633-641$.

Joskow, P.L., 1991. Asset specificity and the structure of vertical relationships: empirical evidence. In: Williamson, O.E., Winter, S.G. (Eds.), The Nature of the Firm: Origins, Evolution, And Development. Oxford University Press, Oxford, pp. 117-137.

Lambertini, L., 1994. Equilibrium locations in the unconstrained Hotelling game. Economic Notes 23, 438-446.

Lambertini, L., 1997. Unicity of the equilibrium in the unconstrained Hotelling model. Regional Science and Urban Economics 27, 785-798.

Lommerud, K.E., Straume, O.R., Sørgard, L., 2003. Downstream merger with upstream market power. European Economic Review, forthcoming.

Mai, C., Peng, S., 1999. Cooperation vs. competition in a spatial model. Regional Science and Urban Economics 29, $463-472$.

Mayer, T., 2000. Spatial Cournot competition and heterogeneous production costs across locations. Regional Science and Urban Economics 30, 325-352.

Neven, D.J., 1986. On Hotelling's competition with non-uniform customer distributions. Economics Letters 21, $121-126$.

Rath, K.P., Zhao, G., 2001. Two stage equilibrium and product choice with elastic demand. International Journal of Industrial Organization 19, 1441-1455.

Riordan, M.H., Williamson, O.E., 1985. Asset specificity and economic organization. International Journal of Industrial Organization 3, 365-378.

Tabuchi, T., Thisse, J.F., 1995. Asymmetric equilibria in spatial competition. International Journal of Industrial Organization 13, 213-227.

Wang, X.H., Yang, B.Z., 1999. On Hotelling's model with a restricted reservation price. Australian Economic Papers 38, 259-275.

Williamson, O.E., 1983. Credible commitments: using hostages to support exchange. American Economic Review $73,519-570$. 